slight rheumatism at the age of twenty-four; he had never had rheumatism until then, but it has since relapsed several times, getting worse at each attack, and has already caused partial ankylosis of one wrist; he has also had several relapses of iritis. Henry $H$. had gout in his right great toe for the first time at the age of fifty, an acute and severe attack, and almost at the same time his left eye inflamed; three years later, he was under care for his second iritis in the same eye; his father was also subject to gout in the great toes.

It is interesting to note in this connection that in none of the cases of relapsing iritis was there any reason to think that the first attack had been syphilitic. This fact, together with the one already mentioned, that cases of syphilitic iritis show no tendency to relapse, supports the view that the recurrences are not due solely, nor even in any considerable degree, to the presence of old adhesions. Whether iridectomy does, or does not, really lessen the risk of relapses, as is so often asserted, it is, of course, next to impossible to show directly by statistics ; I have had only one patient on whom the operation had previously been performed, and in him a relapse occurred three years later. The fact of most weight in favour of the view that adhesions cause the relapses, is seen in the frequency with which the disease recurs in one eye, its fellow often escaping altogether. This, however, is only what we are accustomed to witness in the joints of the same patients, without invoking the aid of adhesions; and it would be easy to cite other instances of recurring local affection, especially of the skin, in which exactly the same part repeatedly suffers.

The rarity with which both eyes suffer at the same time is matter for remark; it is, however, not more striking than the frequency with which the articular symptoms in this class of patients are also confined to a single joint, or to two or more, but often without accurate symmetry. In only two of my cases was rheumatic iritis synchronously symmetrical ; and it curiously happened that in both of these the articular rheumatism was symmetrical too. In two cases, the anterior chamber contained a large quantity of the nearly transparent jelly-like exudation which has been described in rare instances by several observers. One of the patients had had gonorrhoea two years before, but had had no rheumatism with it; the other denied ever having had a gonorrhœa.

In regard to sex and age, about two-thirds (fourteen) of my cases were males, and rather more than one-third (nine) females; in one of the latter, however, the history is imperfect, and the disease may have been syphilitic; she was a married woman, aged 23 . The age at which the first attack took place was, on the average, much higher in the women than in the men. Thus, none of the men were more than fifty-six at the first attack, and more than half were below forty. One patient was only nineteen years old, and had had three attacks by the time he was twenty-three ; it is of interest to note that all his five brothers and his father were subject to gout, and that this disease had also occurred on the father's side two generations earlier. Of the eight women (excluding the one above noted as doubtful), only two were below forty, the remaining six varying in age from fifty-four to sixty-eight when the iritis first occurred. The youngest of the women (Emma R.) was twenty-six when her left eye first inflamed; she had an attack in the right some time afterwards ; and at thirty-three a second in the left. Her father died of "rheumatic gout", and his father also had it ; she herself was liable to stiffness in her elbows and knees, and to severe neuralgia in the head. The second of the youngest women was thirty-six, and her father had also had gout; she had a relapse at the age of thirty-eight.

A certain number of cases (fifteen) remain which have not been classed with either the syphilitic or the arthritic series. Several -were cases of iritis from slight injuries; and in some others, although the history of injury was wanting, there were circumstances which made its occurrence very probable. Two were cases of uncomplicated iritis in children, aged 14 and 15 , and for these I quite failed to find any explanation (published in the Lancet, Jan. 15 th, 1876). I have at present under care a third case in a girl of fifteen, without apparent cause. In two or three others the history was uncertain, but syphilis likely.

A few remain in which there was good evidence that syphilis had occurred some considerable time before the iritis; and, as in cases such as these it may be of importance to establish, as far as possible, the share taken by the syphilis in the production of the iritis, I will mention very shortly the particulars of each.

CASE I. Samuel O. had syphilis severely at the age of twenty-eight three years and a half later, he had a prolonged attack of subacute iritis in his left eye ; the right escaped. He had never had rheumatic symptoms, but his father had been laid up with lumbago.

CASE II. Margaret J. had an illness, accompanied by falling of hair and some rash on the skin, when she was forty; it was probably syphilis; her eyes were "weak" for a short time, but it is very doubt- ful whether she then had iritis. Two years afterwards, I treated her for a tolerably severe iritis in the right eye only. She has had no rheumatism, but her father is crippled by it in his hips.

CASE III. Richard W. is an excellent instance of syphilis occurring in a rheumatic man subject to recurrent iritis; there is no reason for regarding his last attack of iritis as syphilitic. At the age of nineteen, he had gonorrhœea, followed by articular rheumatism. At twenty-nine, his left eye inflamed. At thirty-three, he was laid up for three or four months with "sciatica" in his hips ; very severe pain. The left eye again inflamed when he was thirty-four, the attack lasting nearly three months, and being very painful. At thirty-nine he had syphilis, and the rash was still hanging about him when he came to the hospital, a year and three quarters later (aged forty-one), for his third attack of iritis in the left eye. It was very acute, and came on after he had been for three days feeling shivery and ill from a "bad cold". The eye was soon well ; the right never suffered.

CASE IV. Mrs. B. had iritis of the left only, at the age of forty; many synechiæ formed. She was at the same time suffering from serpiginous ulceration of the skin over the left knee; and a few weeks later had paralysis of the right third nerve, which was cured by large doses of iodide of potassium, with bichloride of mercury. There could be no question that she was remotely syphilitic, but the history was negative. I did not inquire about rheumatism.

CASE v. Mrs. S. had syphilis soon after her only pregnancy at about the age of twenty-four; iritis occurred in the left eye only, and the right did not inflame at all. Twenty years afterwards (aged forty-four), she was admitted with mild but acute iritis of the right eye, complicated with some punctate deposits behind the cornea. She denied all rheumatic history. There were no other signs of syphilis at any time, although she continued to attend for some weeks. A year or more previously, she had had a sore place near the angle of the mouth, and a conspicuous scar had followed; it seemed not unlikely that this might have been a chancre, and that she had had a second attack of syphilis she was untruthful, and I did not place much reliance on her denial of other recent syphilitic symptoms. It may be interesting to mention that she was weak, anæmic, and excessively nervous when first seen, and that her health improved very much under the iodide, although she showed no external signs of syphilis.

In the first three of these instances, the rheumatic history given by the patients furnished an adequate cause for the iritis, and there was no reason for supposing that the syphilis had any influence in determining either the occurrence or character of the iritis. Case IV is certainly peculiar, being an instance of iritis without evident cause in a patient presenting symptoms of late tertiary syphilis; very possibly, however, there was no causal relation between the two affections.

\section{THE TREATMENT OF PHIMOSIS BY DILATATION.}

\section{By R. CLEMENT L U CAS, B.S.,} Assistant-Surgeon to Guy's Hospital.

In the BRITISH MEDICAL JouRnal of October 7 th there appears, under the title of "A New Method of Curing Phimosis", a short account by Dr. Griffith of three cases of phimosis treated by dilatation of the foreskin. One can but wonder that Dr. Griffith should have written of this as a new method. It would, indeed, be strange if so simple a means of treating phimosis had not occurred to surgeons generations ago. It has been practised by Mr. Edward Cock in suitable cases probably for half a century, and has been advocated by others. Thus Dr. Cruise, in the Dublin Ouarterly fournal for 1869, recommends "sudden dilatation", and illustrates a very short paper with drawings of no fewer than four kinds of forceps by which this may be effected. He says: "In conclusion, I beg to say the idea of sudden dilatation as a cure for phimosis is not original with me. I saw the late Dr. Hutton use a dressing-forceps for this purpose fifteen years ago." Mr. Cock used to teach that gradual dilatation was generally to be preferred to immediate distension, and that it was applicable to cases of simple phimosis, when the prepuce was not of immoderate length, and its orifice was not thickened. In slight cases, the patient may be taught to dilate it. For the more severe, Mr. Cock some years ago invented a prepuce-dilator, which is of small size, and may be worn by the patient. It consists of four bars, which are separated by a screw, after the manner of Weiss's urethra-dilator.

That the treatment of phimosis by dilatation is anything but novel is proved by reference to the text-books in every-day use. Erichsen, in his Science and Art of Surgery, vol. ii, p. 755, devotes a paragraph of ten lines to a description of this method of treatment. Bryant, in his Practice of Surgery, vol. ii, p. 156, mentions without approval the 
dilating plan; and Holmes's Surgery, its Principles and Practice, contains the following note, p. 806: "Sir J. Paget has, however, pointed out that in many cases the orifice of the prepuce may be so stretched by constant gentle traction, that the glans can ultimately be exposed and the operation avoided.'

\section{CLINICAL MEMORANDA.}

\section{ALPHOS UNIVERSALIS.}

G. B., A MAN sixty-two years of age, suffered with alphos universalis. He had scaly eruption from head to foot, with much thickening of the true skin and fissures running in different directions. He had weak pulse, small and quick ; but did not complain of anything but malaise and the irritation of the skin from dryness and itching, together with thirst. The tongue was coated. I first gave him liquor potassæ in mixture, and commenced the use of the hot-air bath every night ; the skin to be rubbed well afterwards with an ointment composed of equal parts of creasote and tar ointments. In a few days, I commenced the use of liquor carbonis detergens, five minims in an ounce of quassia to be taken three times a day. These means were continued to the end of November, when his skin was quite clear of any disease. As he complained of some remaining debility, I put him on carbonate of ammonia with tincture of cinchona three times a day.

The reason I have made this case public is, that I wished to give the tar-treatment a full trial without having recourse to arsenic or other medicines, as it is well to have other remedies when the system will not bear that drug. His diet, I should have said, was light, with two glasses of sherry daily. $\mathrm{He}$ continues quite well.

$$
\text { F. FARMER, L.K.Q.C.P. }
$$

\section{CASE OF IDIOPATHIC TETANUS.}

MRS. S. B., aged 52, married, had had five robust male children, all living and adult. She was of spare leucophlegmatic habit; but, with the exception of an attack of enteric fever contracted about six years since, and from which she entirely recovered, her health had always been fair. She was seized on the morning of August 2Ist last with violent convulsions of the trunk and extremities, with trismus and complete aphasia. The eyes, which had the expression they generally assumed in health, moved in their regular axes of vision, though the pupils, which were, perhaps, slightly more than normally dilated, were not actively sensible to light. When she was first seen, the hands were clenched upon the abdomen, which led to the inference that pain existed in that region. There were, at the onset, a few efforts at vomiting ; but nothing was ejected beyond a little slimy mucus. Nothing more could be elicited by any sign or expression; and her condition might have resembled eclampsia, but for the absence of the other ordinary signs of this form of epilepsy. At the beginning, the pulse was small and quick, but improved somewhat in volume afterwards. A little spirit of chloroform with an alkali were given through the teeth, but little of it swallowed; afterwards a turpentine and castor-oil enema, also beef-tea; but both were soon returned.

No food had been taken in the morning preceding the attack; but the patient had retired to bed after partaking of a moderate supper of bread, cheese, and ale; had slept well during the night, and rose earlier in the morning than usual to call up the other inmates. The convulsions continued with little abatement and short periods of intermission until death took place in about nine hours from the com mencement of the attack, a short time preceding which the breathing was somewhat stertorous. As no post mortem examination was made, it was difficult to assign any cause for the attack, cases of which, I believe, are less rare in tropical climates.

\section{J. H. CRISP, M.R.C.S.Eng., Lacock, Wilts.}

\section{A CASE OF INTUSSUSCEPTION IN AN INFANT.}

THE rare occurrence of intussusception in an infant four months old, verified by post mortem examination, induces me to bring it before the readers of the BRITISH MEDICAL JouRnal.

On the evening of March I $2 \mathrm{th}$, I was called to see a child of a railway porter, in consequence of continued fits of screaming and the confined state of the bowels, no motion having passed during the previous five days. The mother stated that the child had suffered from sickness and constipation since his birth, the bowels having been relieved once a day, seemingly with much straining. She had been in the habit of giving him "biscuits ard grucl" in addition to the breast-milk. During the five days previous to my visit, the child had thrown up all his food, and had sudden fits of screaming, lasting a very short time, but occur- ring every ten or fifteen minutes; and, as the bowels had not acted during this time, she had given him some grey powder, but without any effect. On examination, the child seemed to be a well nourished infant, rather feverish, with quick pulse, slightly furred tongue, extremely restless, suddenly screaming, then lying quiet, and, shortly afterwards, again screaming violently and ejecting the contents of the stomach in a stream by a single eftort of vomiting. The abdomen was distended and tympanitic. I ordered hot baths, hot fomentations to the abdomen, and a powder containing two grains of calomel and four grains of powdered jalap, followed by sulphate of magnesia.

On the following morning, as no relief had been obtained, I injected a pint and a half of water and olive-oil, manipulating the abdomen at the same time; and ordered the baths to be continued and castor-oil substituted for the sulphate of magnesia. In the evening, the vomited fluid tinged the linen green; the abdomen had become more distended and tympanitic, but no substance could be detected through the abdominal walls. I ordered the purgative to be discontinued, and gave liquor opii sedativus with sulphuric ether every two hours.

On the 15 th, the pain was greatly relieved, only coming on at intervals of two hours. The other symptoms were about the same as on the previous day. The injections were continued, and, in the evening, a teaspoonful of castor-oil was given. During the night, seven very liquid and offensive motions were passed.

From this time to the 22nd, when he died, no more fæces were passed ; but, at every effort of straining, a little mucus passed, and occasionally a little tinged with blood; the abdomen became immensely distended, the child refusing the breast, and, on the 22nd, his pulse gradually failed. During this time, he had chlorodyne, calomel, etc., and injections of assafotida, which seemed to give much relief from the wind.

On post mortem examination, deep down in the left side of the hypogastric region was found a portion of the ileum invaginated, about four inches long in a curve (to the concavity of which the mesentery was attached) and about an inch and a half in circumference; extremely hard, of a deep bluish-black colour. By traction, using considerable force, I was enabled to withdraw the upper part of the invaginated gut (a few small patches which were most congested giving way), when it assumed its ordinary position, measuring about fifteen inches. The invaginated portion was intensely congested, and small masses of coagulated blood were seen on the mesentery. The other parts of the in testines seemed healthy and devoid of feculent matter, but very much distended with wind. G. F. DE LA COUR, M.D.,

Late Resident-Physician, Birmingham General Dispensary.

\section{THERAPEUTIC MEMORANDA.}

\section{ARTIFICIAL DRUM-HEADS.}

I AM quite satisfied with the substantial admission made by $\mathrm{Mr}$. Lennox Browne, in his communication in last week's JOURNAL, as to his error regarding the form of Yearsley's "artificial tympanum". I could have wished, however, that he had made that admission without enveloping it in a cloud of irrelevant matter calculated to draw off attention from the real point at issue, into which cloud I certainly do not choose to follow.

James Patterson Cassells, Glasgow.

\section{TREATMENT OF ACUTE PNEUMONIA BY TURPENTINE.}

THE oil of turpentine has long been an acknowledged agent of great therapeutic value in acute diseases of the chest. In acute pneumonia, I have used it almost to the exclusion of other remedies. For many years, I have adopted the following treatment with great success.

First, a hot terebinthinate stupe is applied until the skin is well reddened; then a little plain oil of turpentine sprinkled over the affected part ; finally, a blanket wrung out of boiling water covered with a dry blanket. I have had patients delirious and gasping for breath, with sordes on the lips (patients who should have seen the doctor twelve hours previously), fall asleep as the last blanket was applied and awake out of danger. The internal remedies subsequently used were quinine and tincture of perchloride of iron. Diet : milk and water, beef-tea, lemonade ad libitum, occasionally wine. The application of the turpentine to little children must, of course, be modified to suit the age. In all cases, I keep on the swathe three or four days or more uninterruptedly. I have found that, as a rule, the active treatment need not be pursued very long, the patient being generally out of danger in twenty-four or forty-eight hours. The sequela of pneumonia are much modificd ; frequently altogether escaped.

R. E. Power, Dartmoor. 